\title{
Design and Dynamic Analysis of Flywheel
}

\author{
T. Raja Santhosh Kumar', Suresh Babu Koppula ${ }^{2,}$ Cr. Prakash ${ }^{3,}$ D.V.Srikanth ${ }^{4}$ \\ Assistant Professor ${ }^{1}$ Associate Professor ${ }^{2}$ Associate Professor ${ }^{3}$ Professor\& Hod ${ }^{4}$ \\ Department Of Mechanical Engg. St. Martin's Engineering College St. Martin's Engineering College St. \\ Martin's Engineering College Hyderabad
}

\begin{abstract}
A flywheel is an inertial energy-storage device. In this paper totally all dimensions have found theoretically for required power $20 \mathrm{KW}$ and it is rotating from $400 \mathrm{RPM}$ to $410 \mathrm{RPM}$. Fly wheel are modeled in PRO/E 5.0 software and this is analyzed with considering at different time interval and different loading conditions have found from theoretically. Countering the requirement of smoothing out the large oscillations in velocity during the cycle of a mechanism system, a flywheel is designed and analyzed. In that four time intervals are considered like motion less, starting position, changing speed and constant speed. Weight reduction is major important and maintain minimum stresses, here another three type of flywheels have chosen like flywheel with extended hub support, rim type and elliptically rim type.
\end{abstract}

Keywords: design of fly wheel, concentration at different stages, finite element technique.

\section{Introduction}

A flywheel is a rotating mechanical device that is used to store rotational energy. Common uses of a flywheel include. It absorbs mechanical energy and serves as a reservoir, storing energy during the period when the supply of energy is more than the requirement and releases it during the period when the requirement of energy is more than the supply.

Fly wheels are generally using for 1.Providing continuous energy when the energy source is discontinuous. 2 . Delivering energy at rates beyond the ability of a continuous energy source. This is achieved by collecting energy in the flywheel over time and then releasing the energy quickly, at rates that exceed the abilities of the energy source.

Types of flywheels: Depending upon the requirements of I, mass moment of inertia, a flywheel can be classified as follows: 1.Solid circular disc, for small values of I 2.Rim and hub with solid, circular web, for moderate values of I 3.Rim, hub, and spokes, for large values of I 4.Rim, hub, and spokes with split type construction

\section{Literature Review}

Design optimization of flywheel of thresher using fem byS.M.Choudhary and D.Y.Shahare in his study solely focuses on exploring the effects of flywheel geometry on its energy st orage/deliver capability per unit mass, further defined as specific energy. Sudipta Saha, Abhik Bose, G. SaiTejesh, S.P. Srikanth have propose the importance of the flywheel geometry design selection and its contribution in the energy storage performance.

Design of fly wheel

Diameter has chosen according to space requirement as $0.6 \mathrm{~m}$

Required power $=20 \mathrm{Kw}$ and it is rotating from $400 \mathrm{RPM}$ to $410 \mathrm{RPM}$.

STORAGE OF ENERGY = 0.6 KN-M

Speed fluctuation

$C S=N 2-N 1 / N$

$=410-400 / 405$

$\mathrm{N}=$ average speed in RPM

Coefficient of speed fluctuation $=0.02469$

Energy storage $\Delta E=M V^{2} C S$

$600=M\left(\Pi \times 0.6 \times \frac{405}{60}\right)^{2} \times 0.02469$

MASS M=150 KG

$\operatorname{MASS}(\mathrm{M})=\Pi \times \mathrm{X} \times \mathrm{B} \times \mathrm{t} \times \rho$

$150=\Pi$ X 0.6 X 0.118 X t X 7510

Required Thickness $\mathrm{t}=0.089 \mathrm{~m}$

International Conference on Recent Innovations in Civil \& Mechanical Engineering

[i- CAM2K16] DOI: 10.9790/1684-16053045156

$51 \mid$ Page 
Outer diameter of rim $=\mathrm{D}+\mathrm{t}=0.6+0.089$

Outer diameter of rim $=0.6897 \mathrm{~m}$

Inner diameter of rim $=\mathrm{D}-\mathrm{t}=0.6-0.089$

Inner diameter of rim $=0.511 \mathrm{~m}$

Design of shaft hub and key

Power $\mathrm{P}=2 X \Pi X N X T / 60$

$20000=2 X \Pi X 405 X T / 60$

$\mathrm{T}=471.57 \mathrm{~N}-\mathrm{M}$

$\mathrm{N}=$ average speed in $\mathrm{RPM}$

Suppose max torque is equal to twice of mean torque THEN

$=43.14 \mathrm{~N}-\mathrm{M}$

Shear Stresses of for Shaft and Key Material Is $40 \mathrm{~N} / \mathrm{mm}^{2}$

$T_{\max }=\frac{\Pi}{16} \times S \times \mathrm{D}^{3}$

$\mathrm{D}=\left(\frac{16 \times 943.14 \times 10^{3}}{\Pi \times 40}\right)^{1 / 3}$

diameter of shaft. (D) $=49.5 \mathrm{~mm}$

diameter of shaft. $(\mathrm{D})=50 \mathrm{~mm}$

Outside diameter of hub may be assumed as twice the diameter of shaft

Outside diameter of hub $=2 \mathrm{X} \mathrm{D}$

Outside diameter of hub $=100 \mathrm{~mm}$

Suppose let we take Length of hub = width of rim

Length of hub for fly wheel $\mathrm{L}=0.07 \mathrm{~m}$

Width of hub for fly wheel $\mathrm{W}=\frac{D}{4}=\frac{50}{4}$

Width of hub for fly wheel $=12.5 \mathrm{~mm}$

Height of hub for fly wheel $\mathrm{H}=\frac{D}{6}=\frac{50}{6}$

Height of hub for fly wheel $=8.5 \mathrm{~mm}$

Material properties

\begin{tabular}{|l|l|}
\hline Material, class, specification & $\begin{array}{l}\text { Gray cast iron, ASTM 30, SAE } \\
111\end{array}$ \\
\hline Ultimate strength & $\begin{array}{l}\text { Tension }=214 \mathrm{M} . P a, \text { shear }=303 \\
\text { M.Pa }\end{array}$ \\
\hline Modulus of elasticity & $101 \mathrm{G} . \mathrm{Pa}$ \\
\hline density & $7510 \mathrm{~kg} / \mathrm{m}^{3}$ \\
\hline Poisson's ratio & 0.23 \\
\hline
\end{tabular}

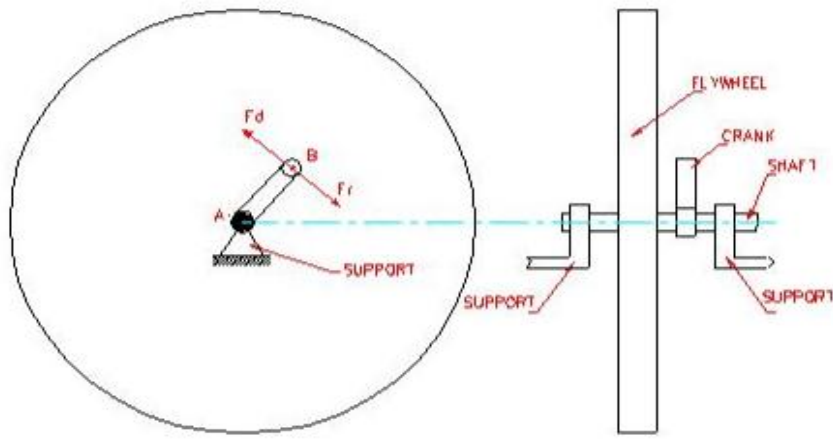

Fly wheel arrangement to support and crank

Design of loading applied in analysis

1.Fly wheel is in motion less : When fly wheel is in motion less position we have to considered as only gravitational force like $9.81 \mathrm{~m} / \mathrm{s}^{2}$. Fly wheel is in starting position: At fly wheel is starting position we are considered the gravitational force and moment of fly wheel and angular velocity changes with respective to time like angular acceleration Force $=9.81 \mathrm{~m} / \mathrm{s}^{2}$

Angular velocity of fly wheel is $=\frac{\text { VELOCITY OF LINK }}{\text { LENGTH OF LINK }}$

$$
=\frac{25}{0.1}=25 \mathrm{rad} / \mathrm{sec}
$$


Here length of link means engine crank length is $0.1 \mathrm{~m}$ And velocity of crank link is $25 \mathrm{~m} / \mathrm{s}$ which is found from velocity diagram. Equivalent inertia of moment of mechanism about point of axis

$\mathrm{j}=$ mass $\mathrm{x}$ length of link

$=150 \times 0.1^{2}$

$=1.5 \mathrm{~kg} \cdot \mathrm{m}^{2},($ Length of crank is $0.1 \mathrm{~m})$

Actual inertia moment of flywheel $=11.7278$

Total moment of inertia $=$ Equivalent inertia of moment + Actual inertia moment

Drive force is equal to $5000 \mathrm{~N}$.

Angular acceleration $=$ drive moment $/$ total moment of inertia

$=5000 \mathrm{X} 0.10 /(11.7228+1.5)$

$=37.799 \mathrm{rad} / \mathrm{sec}^{2}$

Moment applied for fly wheel $=$ actual moment of inertia $\mathrm{X}$ angular acceleration

$=11.7278$ X 37.799

$=221.651 \mathrm{~N}-\mathrm{M}$

Stages considered in flywheel: 1. fly wheel is in motion less 2.fly wheel is in starting 3.flywheel is at changing speed 4. Flywheel is at constant speed

\section{Introduction To Pro/Engineer}

Pro/Engineer Wildfire is the standard in 3D product design, featuring industry-leading productivity tools that promote best practices in design while ensuring compliance with your industry and company standards. Integrated Pro/Engineer $\mathrm{Cad} / \mathrm{Cam} / \mathrm{Cae}$ solutions allow you to design faster than ever, while maximizing innovation and quality to ultimately create exceptional products.

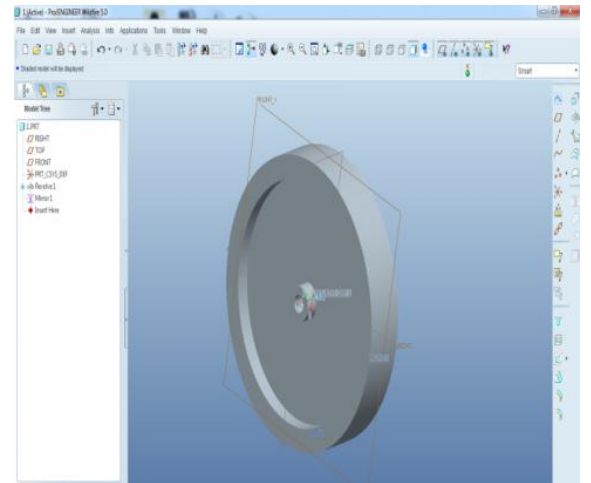

1 st model created in pro/e

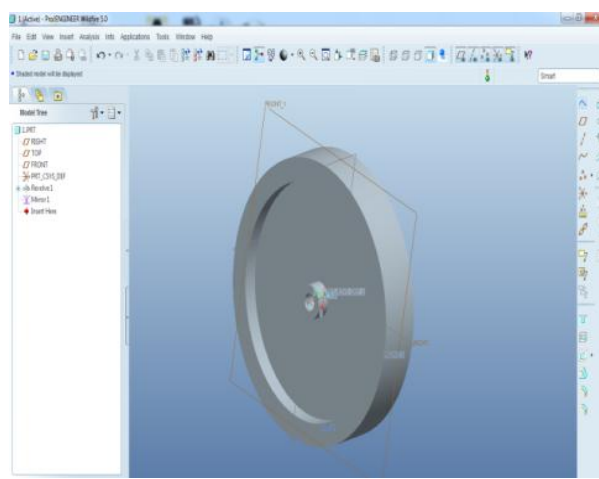

2 nd model created in pro/e

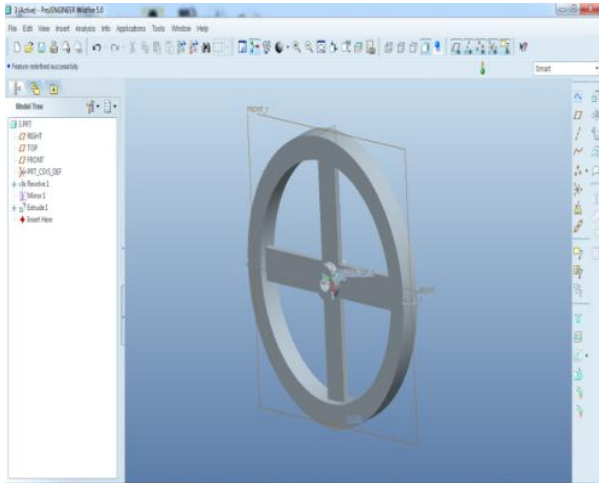

3 rd model created in pro/e

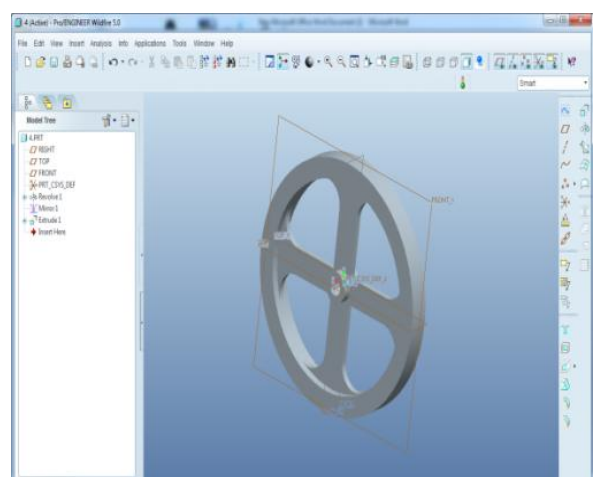

Fourth model created in pro/e

\section{Structural Analysis Of Fly Wheel}

Totally dynamic structural analysis is performed in ANSYS 12.0 software. In that brick 8 node has chosen for solid flywheel. 1/4 models are considered in this analysis. Symmetric boundary conditions are applied and at hub support translation of $\mathrm{x}, \mathrm{y}$ and directions are totally constrained. And rotation $\mathrm{z}$ is released as free to rotate.

In that four time intervals are considered as first fly wheel is in motion less at which self weight is acting, at second interval fly wheel is start position in which moment, self weight and angular acceleration are 
Design And Dynamic Analysis Of Flywheel

applied, at third interval fly wheel is at changing speed at which moment, angular acceleration, angular velocity and self weight is applied and at fourth stage fly wheel is in constant speed at which angular velocity and self is assigned.

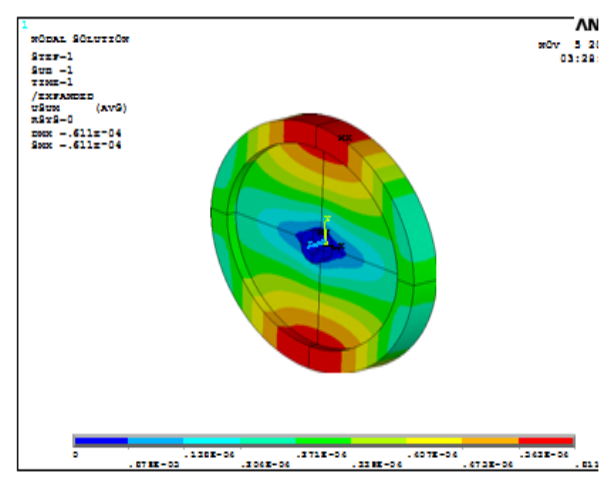

Stresses of 1 st model at $1 \mathrm{sec}$,

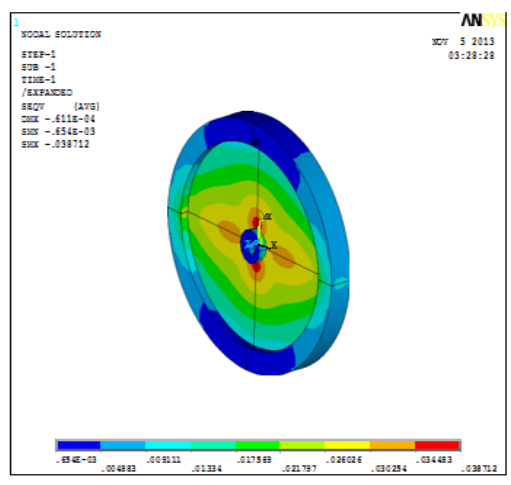

Stresses of $2 \mathrm{nd}$ model at $1 \mathrm{st} \mathrm{sec}$,deformation of 2 nd model at $30 \mathrm{sec}$

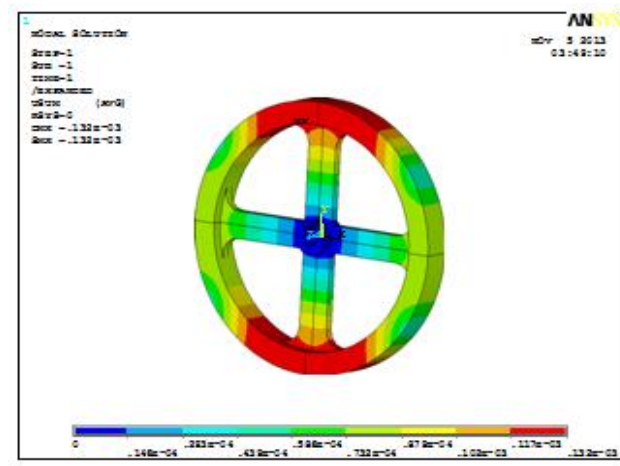

Deformation of 3 rd model at $1 \mathrm{sec}$,

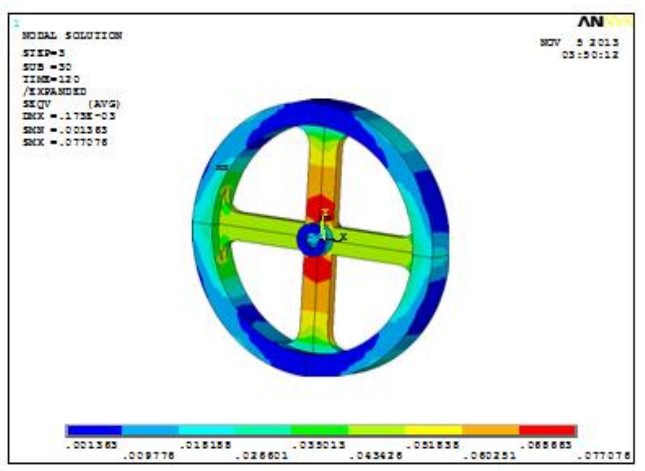

Stresses of 4 th model at $1 \mathrm{sec}$,

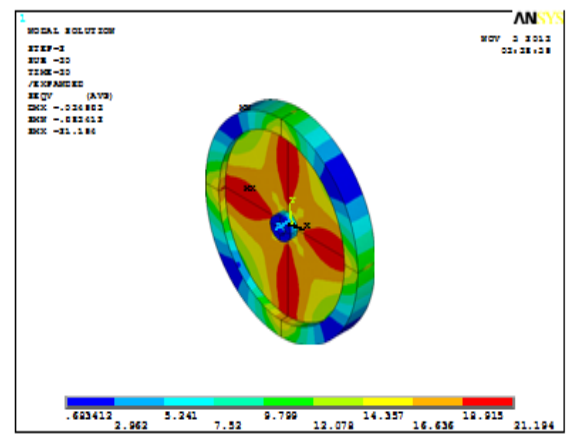

Deformation of 1 st model at $1 \mathrm{sec}$
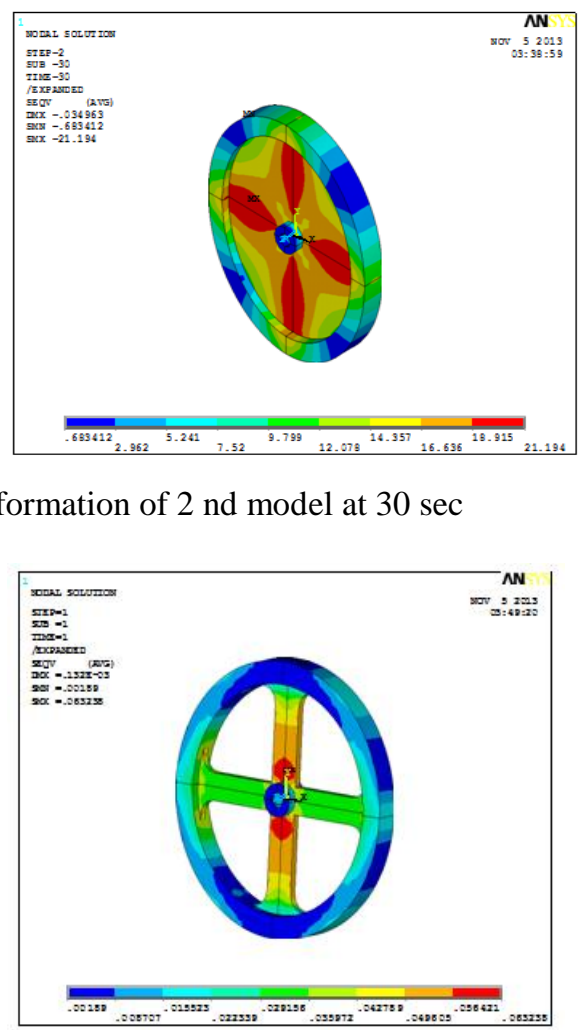

Stresses of $3 \mathrm{rd}$ model at $1 \mathrm{sec}$

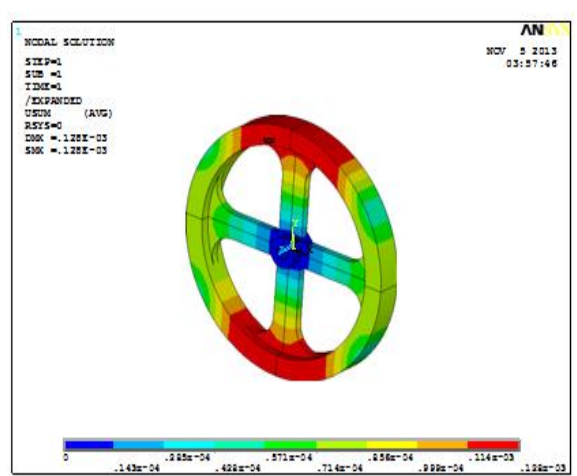

Deformation of 4 th model at $1 \mathrm{sec}$ 
Design And Dynamic Analysis Of Flywheel

\begin{tabular}{|l|l|l|}
\hline \multicolumn{3}{|l|}{ th model } \\
\hline time & deformation & stresses \\
\hline 1 & $1.28 \mathrm{E}-04$ & 0.65391 \\
\hline 30 & 0.086919 & 38.064 \\
\hline 120 & $1.58 \mathrm{E}-04$ & 0.078093 \\
\hline 150 & $2.21 \mathrm{E}-04$ & 0.108759 \\
\hline
\end{tabular}

\begin{tabular}{|l|l|l|}
\hline \multicolumn{2}{|c|}{3 rd model } \\
\hline time & deformation & stresses \\
\hline 1 & $1.32 \mathrm{E}-04$ & 0.6323 \\
\hline 30 & 0.090301 & 39.652 \\
\hline 120 & $1.73 \mathrm{E}-04$ & 0.077076 \\
\hline 150 & $2.33 \mathrm{E}-04$ & 0.1074 \\
\hline
\end{tabular}

\begin{tabular}{|l|l|l|}
\hline \multicolumn{2}{|l|}{ st model } & \\
\hline time & deformation & stresses \\
\hline 1 & $6.11 \mathrm{E}-05$ & 0.038712 \\
\hline 30 & 0.35118 & 21.404 \\
\hline 120 & $5.68 \mathrm{E}-05$ & 0.036 \\
\hline 150 & $4.61 \mathrm{E}-05$ & 0.0294 \\
\hline
\end{tabular}

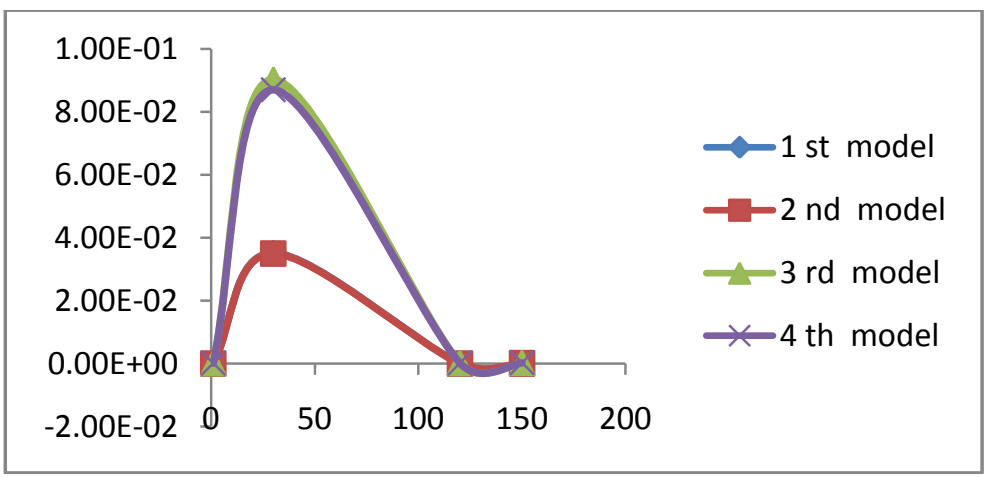

Deformation plot for all models

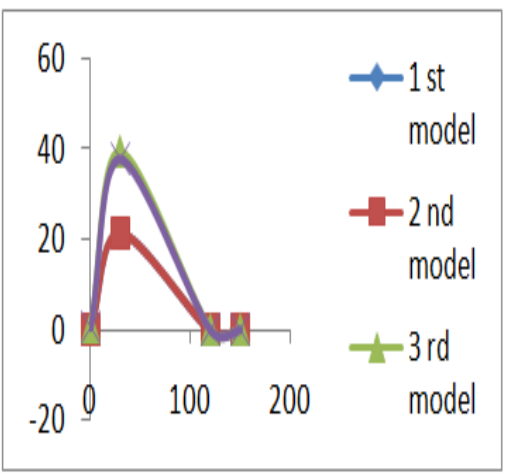

\begin{tabular}{|l|l|l|}
\hline \multicolumn{2}{|l|}{ 2nd model } \\
\hline time & deformation & stresses \\
\hline 1 & $6.09 \mathrm{E}-05$ & 0.038 \\
\hline 30 & 0.03496 & 21.194 \\
\hline 120 & $6.60 \mathrm{E}-05$ & 0.040552 \\
\hline 150 & $9.35 \mathrm{E}-05$ & 0.079077 \\
\hline
\end{tabular}

Stresses plot for all model with respective to time

\begin{tabular}{|r|r|}
\hline MODE SHAPE & FREQUENCY N HZ \\
\hline 1 & 6.27 \\
\hline 2 & 12.57 \\
\hline 3 & 43.21 \\
\hline 4 & 59.48 \\
\hline 5 & 62.94 \\
\hline
\end{tabular}

\begin{tabular}{|r|r|}
\hline MODE SHAPE & FREQUENCY IN HZ \\
\hline 1 & 20 \\
\hline 2 & 36.5 \\
\hline 3 & 57.62 \\
\hline 4 & 90 \\
\hline 5 & 101 \\
\hline
\end{tabular}

1 St Model Frequencies

2 Nd Model Frequencies 
Design And Dynamic Analysis Of Flywheel

\begin{tabular}{|r|r|}
\hline MODE SHAPE & FREQUENCY IN HZ \\
\hline 1 & 4.21 \\
\hline 2 & 11.30 \\
\hline 3 & 37.86 \\
\hline 4 & 46.53 \\
\hline 5 & 57.732 \\
\hline
\end{tabular}

3 Rd Model Frequencies

\begin{tabular}{|r|r|}
\hline MODE SHAPE & FREQUENCY IN HZ \\
\hline 1 & 4.46 \\
\hline 2 & 11.38 \\
\hline 3 & 38.21 \\
\hline 4 & 46.32 \\
\hline 5 & 57.93 \\
\hline
\end{tabular}

4 Th Model Frequencies

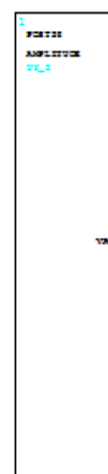

Harmonic analysis results for 1 st model

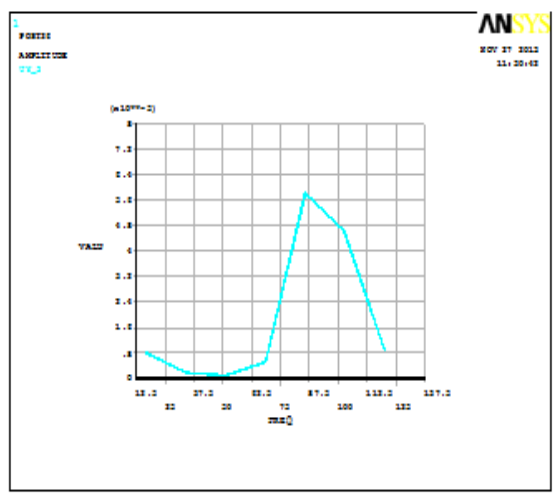

Harmonic analysis results for 2 nd model

\section{Conclusion}

Based on above design and analysis, the following conclusion can be drawn

1. The maximum stress and deflection usually occur at the starting and speed-changing stages, respectively. The situation of stress and deflection at these stages should be paid enough attention.

2. The larger shaft-hole and longer hub are useful to decrease the stress caused by the drive moment.

3. The stress and deflection are alternating transiently as the flywheel is running. These transient changes may lead to the fatigue failure of the flywheel.

4. The stress in the rim is not as large as estimated.

5. The wheel-shaped structure contributes to decrease stress concentration.

6. The wheel-shaped structure is advantageous to get good performance and reduce the cost.

7. The transition through large fillets is favorable to reduce stress concentration at the arms.

8. The over-long arms may result in the large deformation in the rim.

9. There exist certain relationships between angular velocity, stress and deflection at constant speed stage.

10. The good geometry will contribute to decrease the stress concentration in the product and thus improve its lifetime. Free mesh with smart element sizing is useful to mesh complicated mode.

11. Model analysis are performed to find out natural frequencies and where the resonance will occur.

12. Harmonic analysis also performed to find out where the maximum deformation will occur at which frequency.

\section{Reference}

[1]. Zhang Da-lun, Mechanics of Materials, Tongji University Press, Shjanghai, 19931.

[2]. Huang Xi-kai, Machine Design, Higher Education Press, Beijing, 19952.

[3]. Robert L. Norton, Design of Machinery, McGraw-Hill Inc, New York, 19923.

[4]. K. Lingaiah, Machine Design Data Handbook, McGraw-Hill Inc, New York, 19944

[5]. R. S. Khurmi, J. K. Gupta, Machine Design, Eurasia Publishing House, New5.

[6]. Delhi, 1993 